\title{
LAMPU LED BAWAH AIR SEBAGAI ALAT BANTU PEMIKAT IKAN PADA BAGAN APUNG
}

\section{LED UNDERWATER LAMP AS FISH AGGREGATING DEVICE ON BOAT LIFTNET}

\author{
Eko Sulkhani Yulianto ${ }^{1}$, Ari Purbayanto ${ }^{2}$, Sugeng H. Wisudo ${ }^{2}$, Wazir Mawardi ${ }^{2}$ \\ ${ }^{1}$ Program Studi Teknologi Penangkapan Ikan, Sekolah Pascasarjana \\ ${ }^{2}$ Departemen Pemanfaatan Sumbedaya Perikanan \\ Fakultas Perikanan dan Ilmu Kelautan, Institut Pertanian Bogor \\ Korespondensi: ekosulkhaniy@gmail.com,purbayanto@yahoo.com
}

\begin{abstract}
Study on LED underwater lamp as fish aggregating device was conducted todesign and construct the LED underwater lights, to analyze strength of materials used, to analyze the light illumination value and distribution generated from the lamp, and to describe and analyze the test results of the underwater LED lights constructed. This study was divided into three stages, the material testing activities, designing and constructing the LED activities, and the field trials. Based on the results showed that the value of the maximum load that can be retained by the resin ranged from 914.27 to $1177.34 \mathrm{kgf} / \mathrm{cm}^{2}$. The value of the maximum load that can be held by acrylic ranges from 1238.65 to $1539.30 \mathrm{kgf} / \mathrm{cm}^{2}$. Design of instrument built for use in the water, with the material and acrylic resin as a protection/ waterproof. Design of the lamps weremade integrated with a CCTV camera system to facilitate the detection of fish. The LED lights used were a type of RGB High Power LED of 10 watt connected with waterproof driver adjustable step down CC-CV (QSKJ) led driver IN: DC.7-35V OUT: DC.2-30V. The number of drivers used were as many as 9 pieces, where the top of the lamp every 6 pieces of light connected with 1 driver for each color, while for the bottom of every 3 pieces of light connected with 1 pieces driver for each color. The results of measurements of the intensity of light at air showed medium that emits blue light, the most high intensity light than red and white. Type of fish caught during the 5 timesfishing trip was as much as 8 species, consisting of Auxis sp., Loligo sp., Rastrelliger sp., Trichiurus sp., Sardinella sp., Decapterus sp., and Leiognathus sp. The results of tests performed during 5 times fishing trip showed dominant catch of Leiognathus sp. as much as 288 species, and Loligo sp. as much as 266 species.
\end{abstract}

Keywords: construction, Fish Aggregating Device, lift net, under water Light Emitting Diode

\begin{abstract}
ABSTRAK
Penelitian lampu LED bawah air dilakukan untuk merancang dan membuat lampu LED bawah air sebagai alat bantu pemikat ikan, untuk menganalisis kekuatan bahan yang digunakan, untuk menganalisis nilai iluminasi cahaya dan distribusi yang dihasilkan dari lampu, dan untuk mendeskripsikan dan menganalisis hasil tes dari lampu LED bawah air. Penelitian ini dibagi atas tiga tahap, kegiatan pengujian material, perancangan dan pembuatan lampu LED bawah air, dan uji coba lapangan. Berdasarkan hasil penelitian menunjukkan bahwa nilai beban maksimum yang dapat ditahan oleh resin berkisar antara $914.27-1177.34 \mathrm{kgf} / \mathrm{cm}^{2}$. Nilai beban maksimum yang dapat ditahan oleh akrilik 1.238.65-1539.30 $\mathrm{kgf} / \mathrm{cm}^{2}$. Desain instrumen dibangun untuk digunakan dalam air, dengan bahan dan resin akrilik sebagai perlindungan/ tahan air. Desain lampu yang dibuat terintegrasi dengan sistem kamera CCTV untuk memudahkan deteksi ikan. Lampu LED yang digunakan adalah jenis tipe RGB High Power LED 10 watt yang dihubungkan dengan water proof driver step down tipe CC-CV (QSKJ) LED driver dengan spesifikasi IN: DC.7-35V OUT: DC.2-30V. Jumlah driver yang digunakan adalah sebanyak 9 buah, dimana lampu bagian atas sebanyak 6 lampu dihubungkan dengan 1 driver untuk setiap warna. Sedangkan pada lampu bagian bawah, setiap 3 lampu dihubungkan dengan 1 driver pada setiap warna. Hasil pengukuran intensitas cahaya pada medium udara menunjukkan cahaya biru memiliki intensitas yang tertinggi dibandingkan dengan warna merah dan putih. Jenis ikan yang ditangkap selama 5 kali trip bagan apung adalah sebanyak 8 spesies, terdiri dari Auxis sp., Loligo sp., Rastrelliger sp., Trichiurus sp., Sardinella sp., Decapterus sp., dan Leiognathus sp. Hasil pengujian yang dilakukan selama 5 trip menunjukkan tangkapan dominan adalah ikan petek (Leiognathus sp.) sebanyak 288 spesies, dan Loligo sp. sebanyak 266 spesies. Rumpon elektronik pada bagan yaitu dengan menambah intensitas dan daya pada atraktor cahaya, serta adanya kajian lebih dalam terhadap frekuensi suara yang direspon oleh ikan.
\end{abstract}

Kata kunci: alat pemikat ikan, bagan apung, konstruksi, Light Emitting Diode bawah air 


\section{PENDAHULUAN}

Perkembangan perikanan tangkap, salah satunya terjadi karena perkembangan pengetahuan mengenai fish behavior, seperti beberapa jenis ikan ternyata tertarik dengan cahaya. Perkembangan penangkapan menggunakan alat bantu cahaya berkembang terus yang kemudian dikenal dengan istilah light fishing. Pada awalnya sumber cahaya yang digunakan dalam upaya penangkapan ikan adalah obor, namun seiring perkembangan ilmu dan teknologi mulailah digunakan lampu minyak/kerosene, lampu karbit dan perkembangan terakhir dengan penggunaan lampu listrik. Lampu listrik berkembang begitu pesat banyak armadaarmada perikanan yang menggunakan lampu sampai ribuan bahkan puluhan ribu watt. Tetapi masalah yang terjadi adalah apakah penggunaan lampu yang begitu banyak jumlahnya dan begitu besar dayanya sudah efektif, padahal biaya yang dikeluarkan untuk penggunaanya tidaklah sedikit. Dari hasil penelitian sebelumnya dinyatakan bahwa besarnya nilai iluminasi (lux) suatu sumber cahaya akan menurun dengan meningkatnya jarak dari sumber cahaya tersebut, dan nilainya akan berkurang apabila cahaya tersebut masuk ke dalam air karena mengalami pemudaran (Ben Yami 1976).

Selain itu fakta yang terjadi di Palabuhanratu, penggunaan alat tangkap bagan mengalami kecenderungan yang menurun selama periode 2006-2010. Penggunaan alat tangkap bagan di perairan Palabuhanratu pada tahun 2006 adalah sebesar 263 unit namun pada tahun 2009 turun drastis menjadi sebesar 23 buah. Penurunan tersebut dimungkinkan karena adanya pengaruh kebijakan pemerintah dalam konversi minyak tanah ke gas elpiji $3 \mathrm{~kg}$, yang mengakibatkan harga minyak tanah melambung tinggi sehingga biaya operasional bagan meningkat.

Berdasarkan permasalahan tersebut, para peneliti mulai mengembangkan lampu bawah air untuk mengurangi besar penurunan nilai iluminasi yang disebabkan oleh pemudaran akibat perbedaan media rambat cahaya dan mengurangi pemborosan energi untuk penggunaan lampu sebagai alat bantu penangkapan. Pengembangan tersebut melalui penggunaan langsung lampu bawah air sehingga tidak terjadi lagi suatu pembiasan maupun pembelokan cahaya. Kondisi ini diharapkan penggunaan besar sumber cahaya akan lebih efektif dan efisien. Teknologi lacuba sudah diketahui penggunaannya, yaitu sejak tahun 1990an. Namun penggunaan jenis lampu LED (Light Emitting Diode) masih belum banyak diujicobakan. Pemilihan lampu LED didasarkan pada energi yang digunakan jauh lebih hemat. (S.C. Shen \& H.J. Huang 2012) percobaan penggunaan lampu LED untuk penangkapan mengurangi konsumsi BBM sekitar 15-17\%.

Penelitian ini memiliki beberapa tujuan, yaitu mendesain dan mengkonstruksi lampu LED bawah air, menganalisis kekuatan material bahan yang digunakan, menganalisis besar iluminasi dan sebaran cahaya yang dihasilkan dari lampu, dan mendekripsikan hasil uji coba penangkapan dengan lampu LED bawah air. Dalam penelitian ini hanya untuk membuktikan bahwa lampu LED kontruksi mampu mengumpulkan/ memikat ikan dan layak dikembangkan lebih lanjut.

\section{METODE PENELITIAN}

Kegiatan penelitian dibagi dalam tiga tahap, yaitu kegiatan uji coba material bahan yang digunakan, kegiatan perancangan dan pembuatan, dan kegiatan uji coba lapang. Kegiatan uji coba bahan material dilakukan pada bulan Juni 2013 di Laboratorium Keteknikan Kayu Fakultas Kehutanan, Institut Pertanian Bogor, selanjutnya untuk kegiatan perancangan dan pembuatan alat dilakukan pada bulan Mei-September 2013 di Workshop Departemen Pemanfaatan Sumberdaya Perikanan Fakultas Perikanan dan Ilmu Kelautan Institut Pertanian Bogor. Sedangkan kegiatan ujicoba lapang dilakukan pada bulan Oktober 2013 di Perairan Palabuhanratu, Kecamatan Palabuhan Ratu, Kabupaten Sukabumi.

Alat yang digunakan dalam penelitian ini adalah gurinda listrik, bor listrik, solder, timah, digital lux meter, multimeter digital, jigsaw (mesin gergaji listrik). Adapun bahan yang digunakan yaitu RGB high power LED 10 watt, driver LED untuk daya 10 watt 12 volt, kabel-kabel, akrilik $5 \mathrm{~mm}$, polyester resin dan hardener, reflektor diameter 23 mm, saklar-saklar, box (pelican), LED LG 14 inci, CCTV kamera, DVR, hardisk 1 TB, speaker underwater, Sony multiplayer (Gambar 1). 


\section{Analisis data}

\section{Kegiatan pengujian material}

1. Uji tekan material resin dan akrilik

Pengujian material yang dilakukan terhadap bahan yang digunakan dalam pembuatan lampu, yaitu bagian yang digunakan dalam sistem kedap airnya. Bahan yang digunakan meliputi akrilik dan resin. Pengujian dilakukan masing-masing sebanyak 3 kali ulangan. Bentuk dan ukuran contoh uji untuk pengujian keteguhan tekan disesuaikan dengan standar Japan International Standard. Ukuran dan bentuk contoh uji disajikan pada (Gambar 2). Pengujian mekanis contoh uji dilakukan di Laboratorium Keteknikan Kayu, Departemen Teknologi Hasil Hutan, Fakultas Kehutanan, Institut Pertanian Bogor. Untuk pengujian kekekuatan mekanis bahan, digunakan alat uji tekan Universal Testing Machine (UTM) instron.

2. Prosedur perhitungan hasil pengujian

Nilai-nilai dari hasil uji kekuatan tekan dihitung menggunakan rumus tertentu. Selanjutnya diuraikan cara perolehan data dari beberapa sifat fisik dan mekanis dari material akrilik dan resin. Keteguhan tekan maksimum adalah kemampuan suatu contoh uji untuk menahan beban yang diberikan secara perlahan-lahan yang semakin lama semakin besar sampai contoh uji mengalami kerusakan. Perhitungan untuk menentukan kekuatan tekan berdasarkan persamaan berikut (Haygen \& Bowyer 1989):

$$
\mathrm{tk}=\frac{\text { Pmaks }}{A}
$$

Keterangan:

tk $=$ Keteguhan tekan maksimum $\left(\mathrm{kgf} / \mathrm{cm}^{2}\right)$

Pmaks = Beban maksimum sampai terjadi kerusakan (kgf)

$A=$ luas penyangga $(\mathrm{cm})$

\section{Pembuatan LED bawah air}

Pengumpulan data proses pembuatan lampu LED bawah air adalah dengan mendokumentasikan semua proses tahapan pembuatan lampu mulai dari awal hingga selesai. Analisis yang digunakan adalah analisis dekriptif yaitu menjabarkan proses pembuatan serta pemilihan bahan yang digunakan, didukung dengan referensi serta spesifikasi dari bahan material yang digunakan.

Prosedur pengukuran iluminasi cahaya dilakukan untuk mengetahui pola sebaran cahaya lampu LED yang dibuat. Pengukuran cahaya dilakukan pada 3 (tiga) warna cahaya yang berbeda yaitu, merah, putih, dan biru. Pengukuran dilakukan secara horizontal pada setiap kelipatan sudut $10^{\circ}$ pada jarak $0.50 \mathrm{~m}, 1 \mathrm{~m}, 1.50 \mathrm{~m}$ dan $2 \mathrm{~m}$ pada medium udara. Pengukuran dilakukan pada posisi pengukuran horizontal dan vertikal terhadap arah lampu (Gambar 3).

\section{Uji coba penangkapan}

Uji coba alat dilakukan dengan tujuan untuk mengetahui kemampuan lampu LED bawah air dalam mengumpulkan serta mengkonsentrasikan ikan dalam jaring bagan. Untuk mengetahui pengamatan bawah air dengan menggunakan kamera video yang sudah terintegrasi pada sistem lampu. Analisis yang digunakan adalah analisis dekriptif yaitu menjabarkan proses penangkapan serta jumlah dan jenis tangkapan.

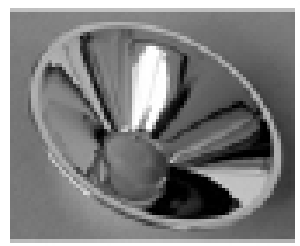

Reflektor

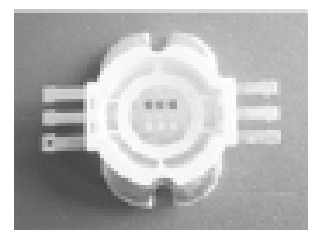

RGB Light Power LED 10 watt

Gambar 1. Bahan dan komponen lampu LED bawah air 

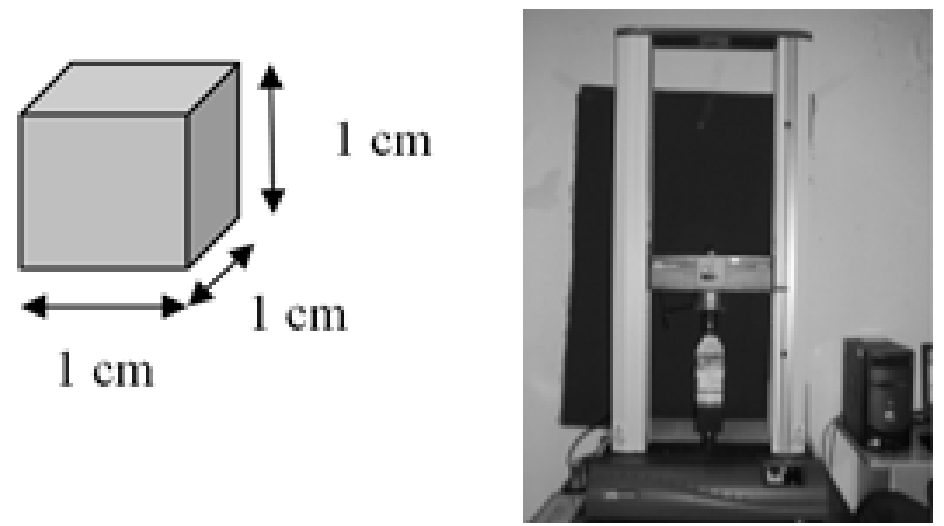

Gambar 2. Material dan alat uji tekan
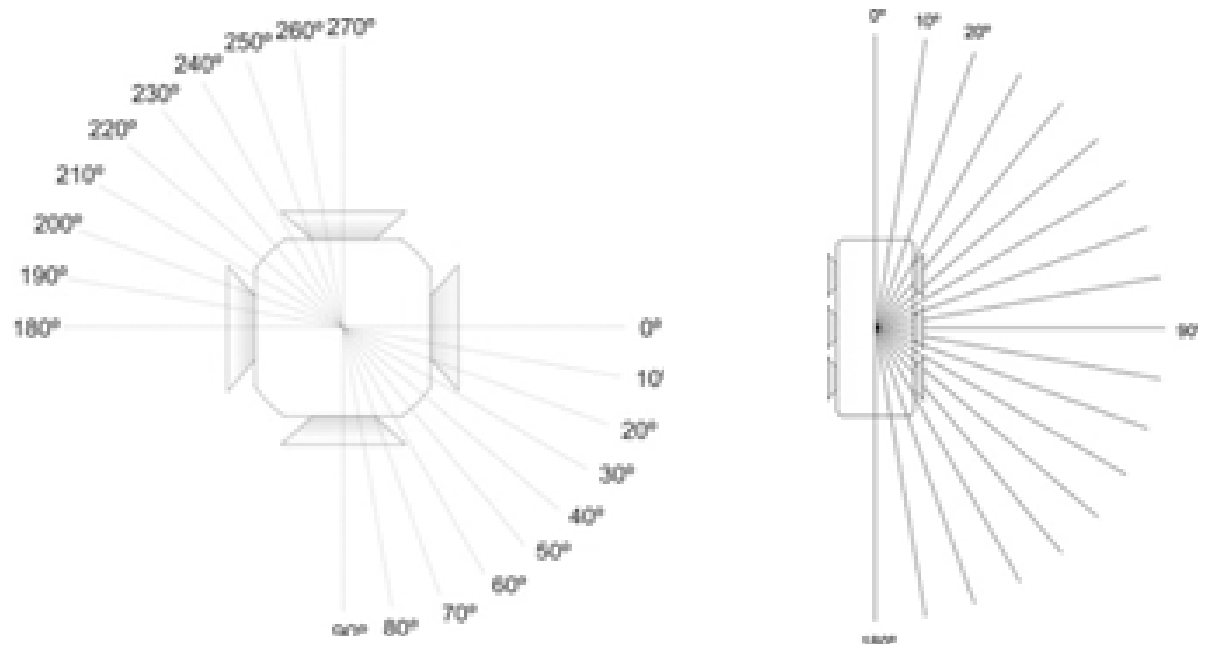

Gambar 3. Posisi pengukuran lampu secara horizontal dan vertikal

\section{HASIL DAN PEMBAHASAN}

\section{Uji material resin dan akrilik}

Uji material dilakukan untuk mengetahui kekuatan tekan dari material yang digunakan yaitu resin dan akrilik. Hal ini berkaitan ketahanan alat, mengingat pengoperasian alat didalam air hingga kedalaman tertentu sehingga alat harus tahan terhadap kebocoran dan tahan terhadap tekanan hingga tekanan tertentu sesuai kedalaman alat dioperasikan. Seperti yang diketahui bahwa tekanan hidrostatik bertambah secara konstan seiring dengan bertambahnya kedalaman air. Setiap kedalaman $10 \mathrm{~m}$ tekanan hidrostatik bertambah sebesar $1 \mathrm{~atm}$ yang setara dengan $1.03 \mathrm{~kg} / \mathrm{cm}^{2}$ atau $14.70 \mathrm{lbs} / \mathrm{in}^{2}$.

Berdasarkan hasil uji laboratorium terhadap uji tekan akrilik dan uji tekan resin menunjukkan bahwa nilai beban maksimum yang dapat ditahan oleh resin perlakuan uji tekan pada tiga sampel yang diujicobakan berkisar antara 914.27-1177.34 kgf $/ \mathrm{cm}^{2}$, nilai beban maksimum yang dapat ditahan oleh akrilik yang diujicobakan pada ketiga sampel uji adalah berkisar antara 1238.65$1539.30 \mathrm{kgf} / \mathrm{cm}^{2}$ seperti yang disajikan pada (Gambar 4).

Material resin digunakan untuk membungkus lampu, sehingga lampu lebih solid dan tahan getaran, berfungsi sebagai penahan dari tekanan air dan melindungi lampu dari kemungkinan rembesan air sehingga umur lampu bisa tahan lama (Li Tian Hua \& Jing Xing 2013).

\section{Rancangan dan konstruksi lampu bawah air}

Rencana desain awal alat dibangun untuk penggunaan di dalam air yang bertujuan untuk mengurangi pemudaran 
yang disebabkan perbedaan media rambat cahaya. Oleh karena itu pemilihan bahan juga sangat diperhatikan terutama untuk melindungi bagian dari lampu yang terendam dalam air. Hal senada dikemukakan oleh Callister (2004) \& Smith (1996) bahwa dalam merancang atau mendesain sebuah produk terdapat persyaratan terkait dengan sifat dari produk yang ingin dibuat, pemilihan material menjadi salah satu yang harus dipertimbangkan dan harus memperhatikan fungsi (function), batasan (constrain), tujuan (objective), dan variabel bebas (free variables). Selain itu lampu juga dirancang untuk memudahkan penggunanya atau nelayan dalam mendeteksi keberadaan ikan sehingga terintegrasi dengan kamera dan monitor pengamatan di bagian panel peng-operasian. Rangkaian desain lampu disajikan pada (Gambar 5).

\section{Sistem lampu}

Sistem lampu merupakan bagian utama dan komponen terpenting dari kontruksi rangkaian lampu LED bawah air, oleh karena itu banyak pertimbangan yang harus diperhatikan agar lampu LED bawah air dapat digunakan dengan baik dan bertahan lama. Salah satu faktor penting yang dipertimbangkan adalah dalam penggunaan material. RGB High Power LED 10 watt yang digunakan sebanyak 15 lampu, dimana pada setiap sisi terdiri dari 3 buah lampu yang dirangkai secara paralel. Lampu LED dipasang pada hollow aluminium persegi (lampu samping) dan plat aluminium (lampu bawah) dengan bantuan tube glue thermal adhesive yang berfungsi sebagai perekat sekaligus penghantar panas yang dihasilkan Lampu LED, sehingga panas yang dihasilkan oleh lampu terserap oleh aluminium. Oleh karena itu, penggunaan aluminium berfungsi sebagai peredam panas (heatsink) dan untuk memaksimalkan peredaman panas pada bagian dalam hollow aluminium ditambahkan sirip aluminium pada sisi dalam hollow aluminium, serta desain yang terbuka sebagai aliran air. Penggunaan material aluminium juga dinilai lebih tahan terhadap korosif dibandingkan dengan besi. Seperti yang dikemukakan Priyotomo (2008) bahwa logam aluminium umum digunakan di bidang penerbangan, otomotif dan sebagainya dikarenakan mempunyai ketahanan terhadap korosi atmosfer. Adapun skema rangkaian eletronik dari lampu led disajikan pada (Gambar 6). RGB High Power LED 10 watt yang telah terpasang disambungkan dengan driver RGB yang berfungsi sebagai stabilizer atau pengatur tegangan yang dihasilkan dari input tegangan sehingga input tegangan yang masuk ke lampu menjadi stabil. Tipe driver yang digunakan adalah Waterproof Adjustable Step Down CC-CV (QSKJ) LED Driver IN: DC.7-35V OUT:DC.2-30V. Adapun jumlah driver yang digunakan adalah sebanyak 9 buah, dimana pada lampu bagian atas setiap 6 buah lampu dihubungkan dengan 1 buah driver untuk setiap warnanya, sedangkan untuk bagian bawah setiap 3 buah lampu dihubungkan dengan 1 buah driver untuk setiap warnanya. Setelah semua komponen elektronika terangkai, untuk bagian kedap air digunakan resin untuk mengecor bagian lampu. Pada sistem lampu dibuat massive tidak ada rongga udara seperti semacam casing underwater bertujuan agar lampu lebih berat dan tenggelam sehingga cenderung lebih dapat stabil walaupun terkena arus. Hal ini didasarkan pada literatur yang menjelaskan bahwa justru cahaya terang yang tidak stabil/ berubahubah akan menakutkan bagi ikan (fickering light). Adanya kemungkinan arus kuat dan gelombang besar jelas akan mempengaruhi kedudukan lampu (Subani dan Barus 1988). Makin besar gelombang makin besar pula flickering light yang terjadi dan makin besar hilangnya efisiensi sebagai daya penarik perhatian ikan-ikan maupun biota lainnya menjadi lebih besar karena ketakutan. Selain itu, pertimbangan lain yaitu apabila didesain semacam casing underwater akan ada kemungkinan embun di dalam lampu karena adanya ruang udara di dalamnya. Pengembunan bisa terjadi kondensasi udara dalam lampu. Desain dan konstruksi lampu dapat dilihat pada Gambar 7.

\section{Sistem perekaman (recording)}

Sistem perekaman dibuat bertujuan supaya lebih memudahkan pengguna/ nelayan, sehingga ketika pengoperasian dilakukan nelayan/user dapat melihat langsung keberadaan ikan di sekitar lampu. Sistem perekaman yang digunakan adalah dari jenis kamera infra-red yang sering digunakan dalam sistem keamanan (CCTV) yang terhubung dengan DVR dan langsung dapat terpantau dengan layar monitor (merek LED LG 14 inch). Pemilihan kamera infra-red dimaksudkan agar sistem masih dapat merekam atau memantau ikan-ikan yang berkumpul disekitar lampu 
walaupun lampu dalam keadaan gelap. Agar sistem perekaman dapat disimpan, sistem dilengkapi dengan media penyimpanan (harddisk) sebesar 1 TB (terabyte). Unit sistem lampu dan unit saklar disajikan pada Gambar 8.

\section{Uji sebaran cahaya}

Bentuk kontruksi mempengaruhi pola sebaran cahaya yang dihasilkan oleh lampu. Untuk memudahkan pengukuran lampu, pengukuran hanya dilakukan pada 2 sisi lampu atau sudut $0-180^{\circ}$, dan untuk sudut $180-360^{\circ}$ dianggap nilainya sama, baik pengukuran secara horizontal maupun vertikal. Hal ini dikarenakan pengaruh desain bentuk yang simetris dan jenis maupun jumlah lampu yang digunakan sama.

Hasil pengukuran intensitas cahaya pada medium udara menunjukkan bahwa cahaya warna biru memancarkan intensitas paling tinggi dibandingkan cahaya lainnya (merah dan putih) untuk jarak pengukuran yang sama. Intensitas cahaya tertinggi dihasilkan pada posisi searah cahaya lampu atau sudut $0^{\circ}$ dan $90^{\circ}$ terhadap arah lampu dan intensitas cahaya terendah dihasilkan pada posisi sudut $30-50^{\circ}$ terhadap arah lampu. Hal ini dapat dipahami karena bentuk kontruksi dari lampu bawah air yang berbentuk balok.

Kisaran intensitas cahaya merah yang dihasilkan pada jarak 0.50 meter berkisar antara 256-385 lux. Terjadi penurunan iluminasi yang cukup signifikan terjadi pada pengukuran dengan jarak 1 meter, intensitas cahaya yang terukur pada jarak 1 meter berada pada kisaran 73-101 lux. Sedangkan hasil pengukuran pada jarak 1.50 meter terukur pada kisaran 61-68 lux. Iluminasi cahaya yang terukur terus mengalami penurunan seiring bertambahnya jarak. Hasil pengukuran secara vertikal, pola sebaran cahaya merah lampu LED pada sudut tertentu membentuk motif seperti kupu-kupu. Pengukuran intensitas cahaya tertinggi dihasilkan pada kisaran sudut $90^{\circ}-120^{\circ}$ atau posisi tengah tengah lampu. Profil sebaran cahaya lampu warna merah disajikan pada Gambar 9.

Sebaran cahaya biru yang dihasilkan oleh lampu LED membentuk pola yang sama dengan sebaran cahaya merah yaitu cenderung bermotif bunga pada jarak pengukuran 0.50 meter, membentuk pola lingkaran pada jarak pengukuran 1 meter ke atas. Kisaran intensitas cahaya biru yang dihasilkan pada jarak 0.50 meter berkisar antara 256-385 lux. Terjadi penurunan intensitas yang cukup signifikan terjadi pada pengukuran dengan jarak 1 meter, intensitasnya berada pada kisaran 73-101 lux, sedangkan hasil pengukuran pada jarak 1.50 meter terukur pada kisaran 61-68 lux. Adapun pola sebaran ditunjukkan pada (Gambar 10).

Cahaya warna putih merupakan kombinasi dari warna merah, hijau dan biru. Cahaya warna putih dihasilkan ketika ketiga warna tersebut dinyalkan secara bersamasama. Berbeda dengan pola sebaran cahaya merah dan cahaya biru yang cenderung membentuk pola sebaran membentuk bunga persegi dan intensitas tinggi dihasilkan pada sudut-sudut yang sejajar dengan lampu, pada cahaya berwarna putih justru intensitas cahaya lampu tertinggi pada sekitar sudut $10-20^{\circ}$ dari arah lampu dan membentuk pola sebaran menyerupai bunga berbentuk segi enam, hal ini dimungkinkan reflektor lebih sempurna dalam memantulkan cahaya putih dibandingkan warna lain karena cahaya warna putih senderung lebih menyebar dan warna lainnya cenderung lurus. Pola sebaran cahaya lampu LED warna putih dan pola intensitas penurunannya disajikan pada (Gambar 11).

Nilai-nilai iluminasi tersebut masih dalam kisaran yang adapted bagi ikan. Seperti penelitian Baskoro (2000), yang mengemukakan bahwa tingkah laku pergerakan ikan teri dan adaptasinya terhadap cahaya pada alat tangkap bagan apung dengan menggunakan lampu petromak yang hasilnya ikan teri sangat responsif terhadap cahaya dan berada pada kedalaman kolom air 2-5 meter dengan intensitas 25 lux dan 4 lux.

Nilai-nilai iluminasi cahaya pada ketiga warna cahaya yang diukur menunjukkan nilai-nilai yang berbeda, jarak pengukuran pada masing-masing sudut pengukuran memberikan pengaruh terhadap nilai iluminasi, dimana pengaruh yang diberikan berbentuk persamaan eksponensial. Hal tersebut bermakna bahwa nilai intensitas cahaya terus menurun seiring bertambahnya jarak pengukuran. Berbagai sudut pengukuran yang dibentuk memberikan hasil yang berbeda terhadap nilai persamaan eksponensial pada masingmasing warna cahaya. Nilai-nilai persamaan eksponensial untuk setiap lampu pada sudut-sudut tertentu disajikan pada (Gambar 12). 


\section{Uji coba penangkapan menggunakan e-FAD hasil rekayasa}

Uji coba penangkapan ikan yang dilakukan untuk membuktikan bahwa lampu LED hasil rekayasa dapat digunakan untuk mengumpulkan ikan, sebagai percobaan awal dari alat, yang diharapkan dapat dikembangkan lebih lanjut. Uji coba penangkapan ikan dilakukan sebanyak 5 kali trip, dengan uji coba warna cahaya yang berbeda-beda pada setiap trip. Jenis ikan yang tertangkap selama 5 kali trip adalah sebanyak 8 jenis spesies yang terdiri dari tongkol (Auxis sp.), cumi (Loligo sp.), kembung (Rastrelliger sp.), layur (Trichiurus sp.), tembang (Sardinella $s p$.), layang (Decapterus $s p$.) dan pepetek (Leiognathus sp.). Hasil uji coba penangkapan yang dilakukan selama 5 kali trip, hasil tangkapannya didominasi pepetek (Leiognathus sp.) sebanyak 288 ekor dan cumi (loligo sp.) sebanyak 266 ekor. Hasil tangkapan paling sedikit adalah layur (Trichiurus $s p$.) hanya sebanyak 2 ekor. Secara rinci jumlah hasil tangkapan disajikan pada Gambar 13.

Ketika uji coba penangkapan dilakukan merupakan musim paceklik/ musim sedikit ikan, terbukti dari hasil tangkapan bagan lain yang berdekatan dengan bagan yang digunakan untuk uji coba penangkapan juga menunjukkan hasil yang relatif sedikit (hanya berkisar 1-2 kg), bahkan ada beberapa yang nihil.

Berdasarkan hasil uji coba penangkapan menunjukkan bahwa lampu LED hasil rekayasa bisa digunakan dan mampu mengumpulkan ikan. Dokumentasi rekaman kamera bawah air menunjukkan ikan berenang bergerombol mengitari cahaya lampu, meskipun jumlah gerombolan tidak besar. Dokumentasi hasil rekaman kamera ditunjukkan pada Gambar 14. Banyak sedikitnya hasil tangkapan ikan menggunakan bagan, dipengaruhi oleh banyak faktor yang diantaranya pengaruh musim ikan dan posisi penempatan bagan, pengaruh faktor oseanografi, pengaruh sinar bulan dan sebagainya. Faktor musim sangat berpengaruh terhadap keberadaan ikan, hal ini terbukti dari hasil tangkapan uji coba penangkapan dan bagan-bagan sekeliling yang berdekatan yang dilakukan pada bulan Oktober yang merupakan musim peralihan untuk kawasan Perairan Palabuhan Ratu mendapatkan jumlah hasil tangkapan yang sedikit, justru bagan-bagan yang berada disekitar atau dekat dengan pantai mendapatkan hasil tangkapan yang lebih banyak dibandingkan bagan yang digunakan untuk ujicoba dan bagan-bagan yang disekitarnya yang penempatan posisi jauh lebih ke tengah laut. Selain itu faktor oseanografi juga berpengaruh pada hasil tangkapan bagan, seperti yang dikemukakan Sudirman et al. (2006) yang mengemukakan bahwa hubungan faktor kecerahan dan kecepatan arus pada kedalaman tertentu terhadap hasil tangkapan berpengaruh nyata, terutama untuk kegiatan hauling pada aktivitas bagan apung. Wollburg $\mathrm{P} \&$ Mill E (2013) mengemukakan bahwa warna cahaya, distribusi cahaya, kejernihan air (kekeruhan), dan ikan hilang selama jaring diangkat mempengaruhi keberhasilan penangkapan.

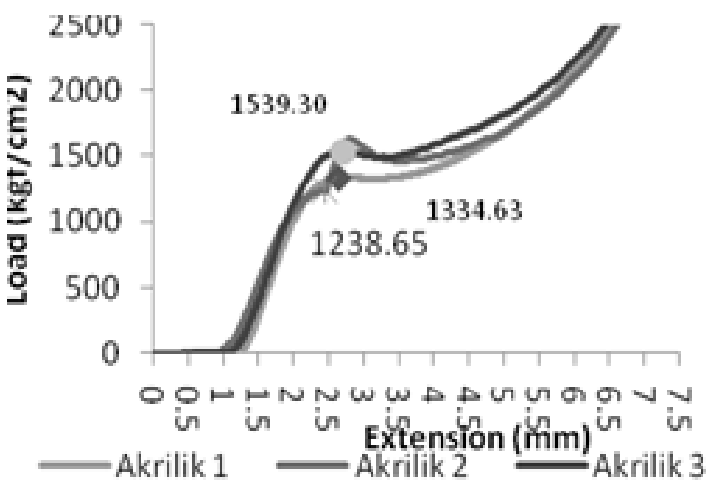

Gambar 4. Kurva hubungan load-extension pada uji tekan 


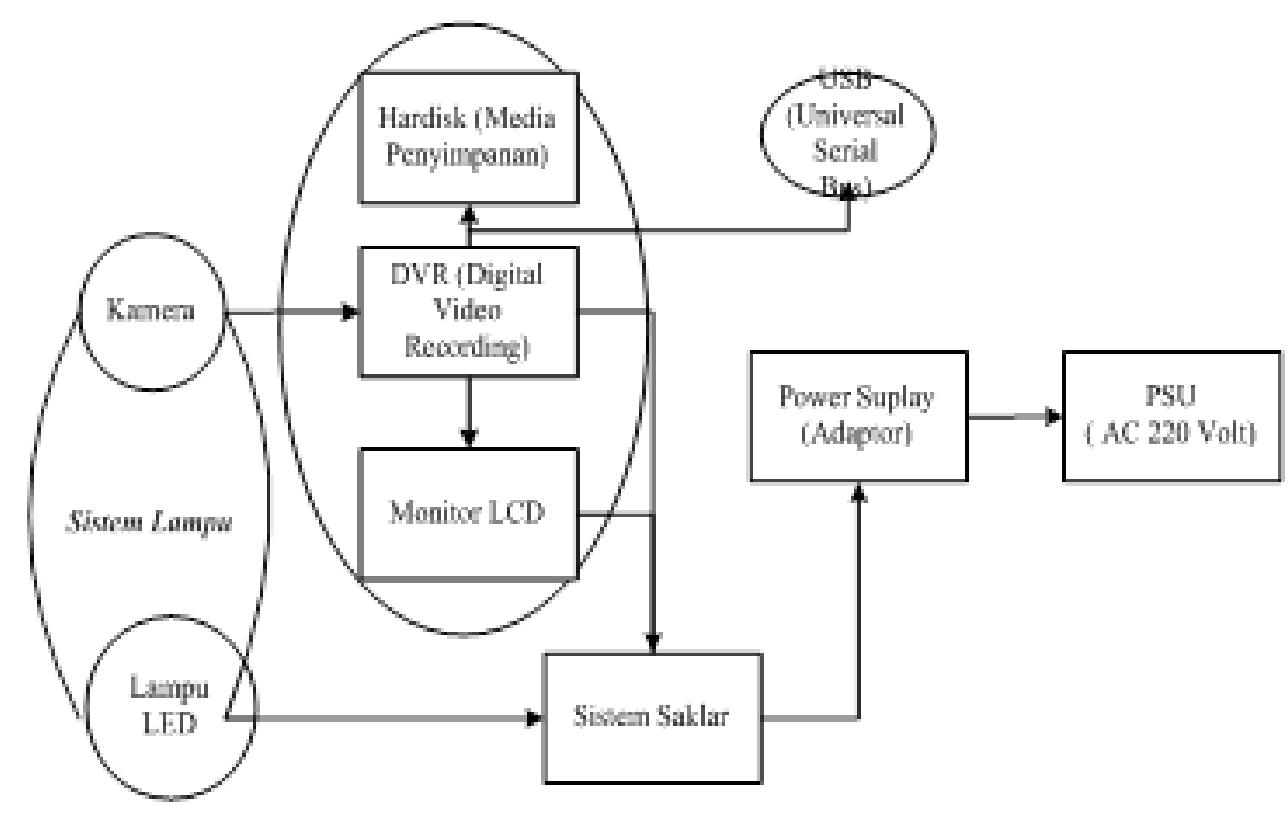

Gambar 5. Sistem rangkaian desain lampu LED bawah air

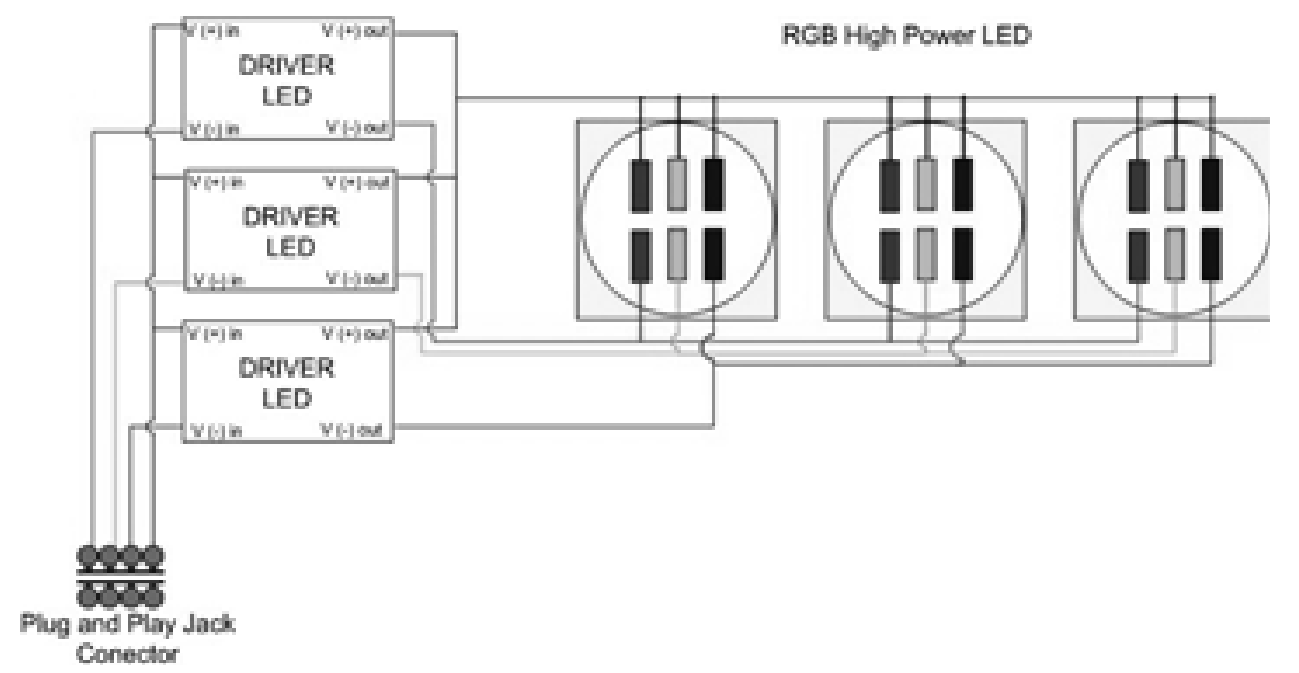

Gambar 6. Skema rangkaian elektronika lampu LED
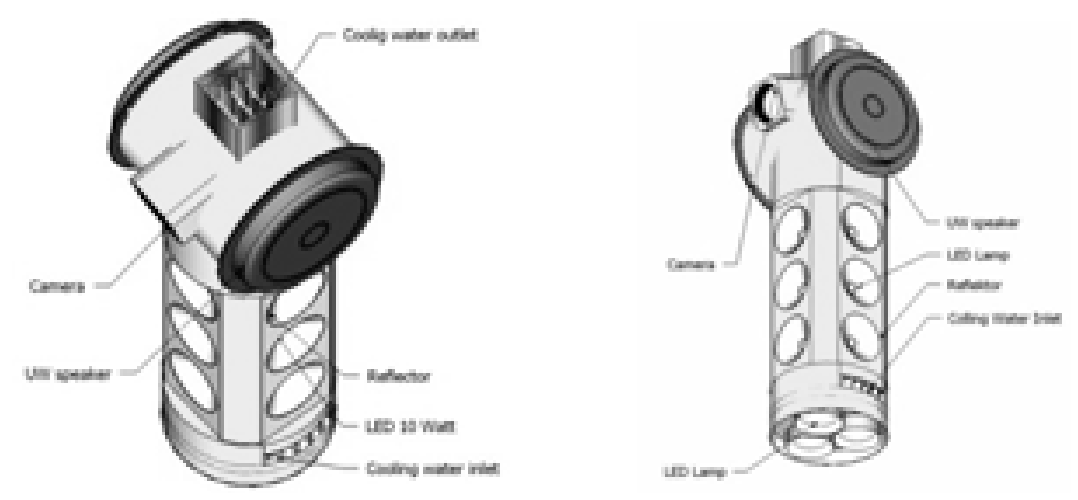

Gambar 7. Desain konstruksi sistem lampu 


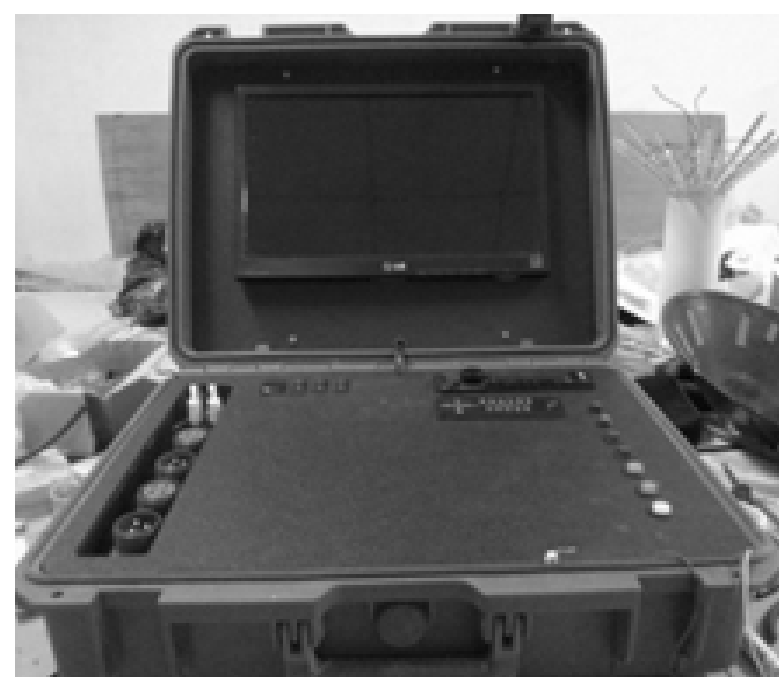

(a)

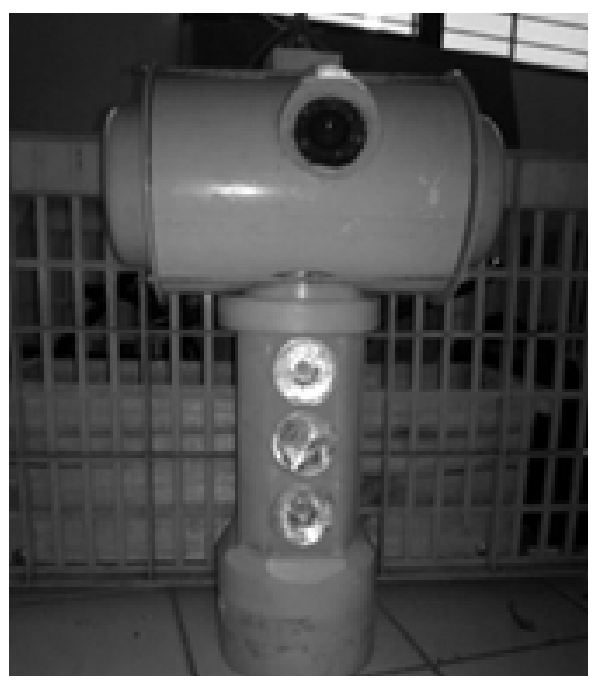

(b)

Gambar 8. Media penyimpanan (recording) beserta media pengamatan terintegrasi dengan monitor pengendali (a) dan kamera terintegrasi dengan sistem lampu (b)

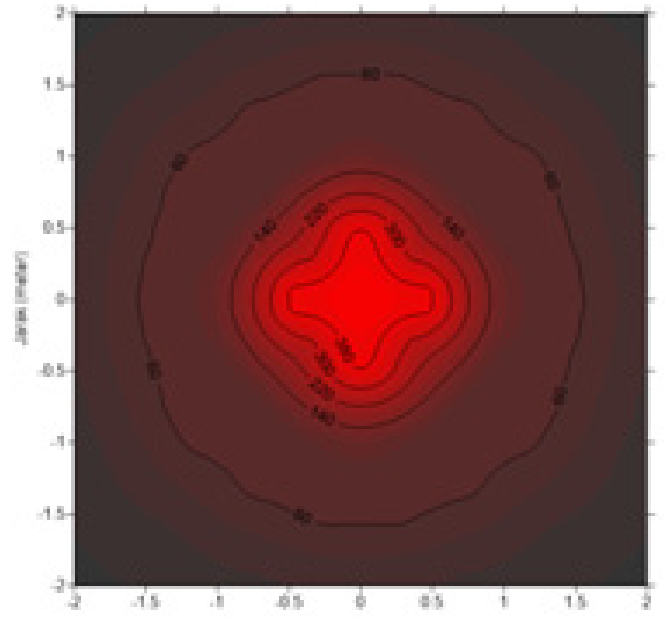

(pengukuran horizontal)

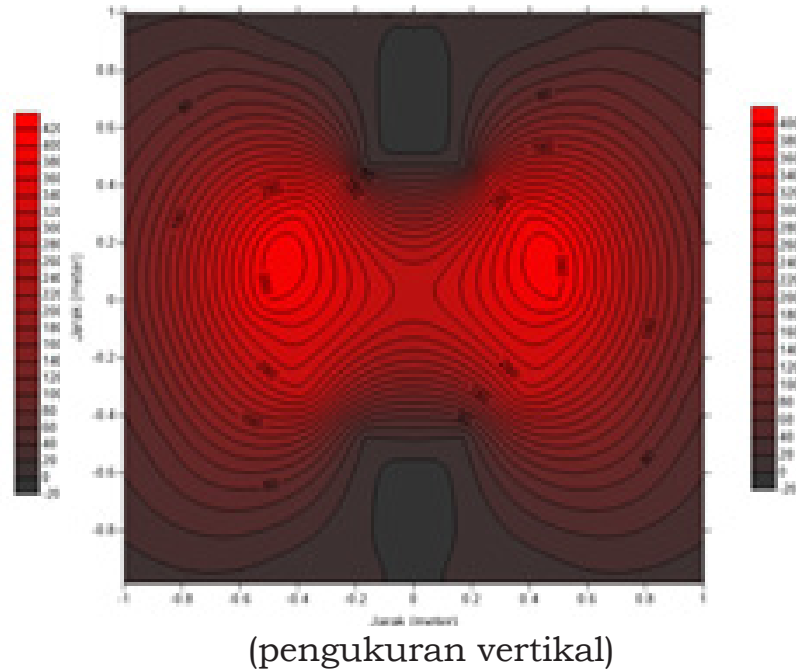

Gambar 9. Pola sebaran cahaya merah
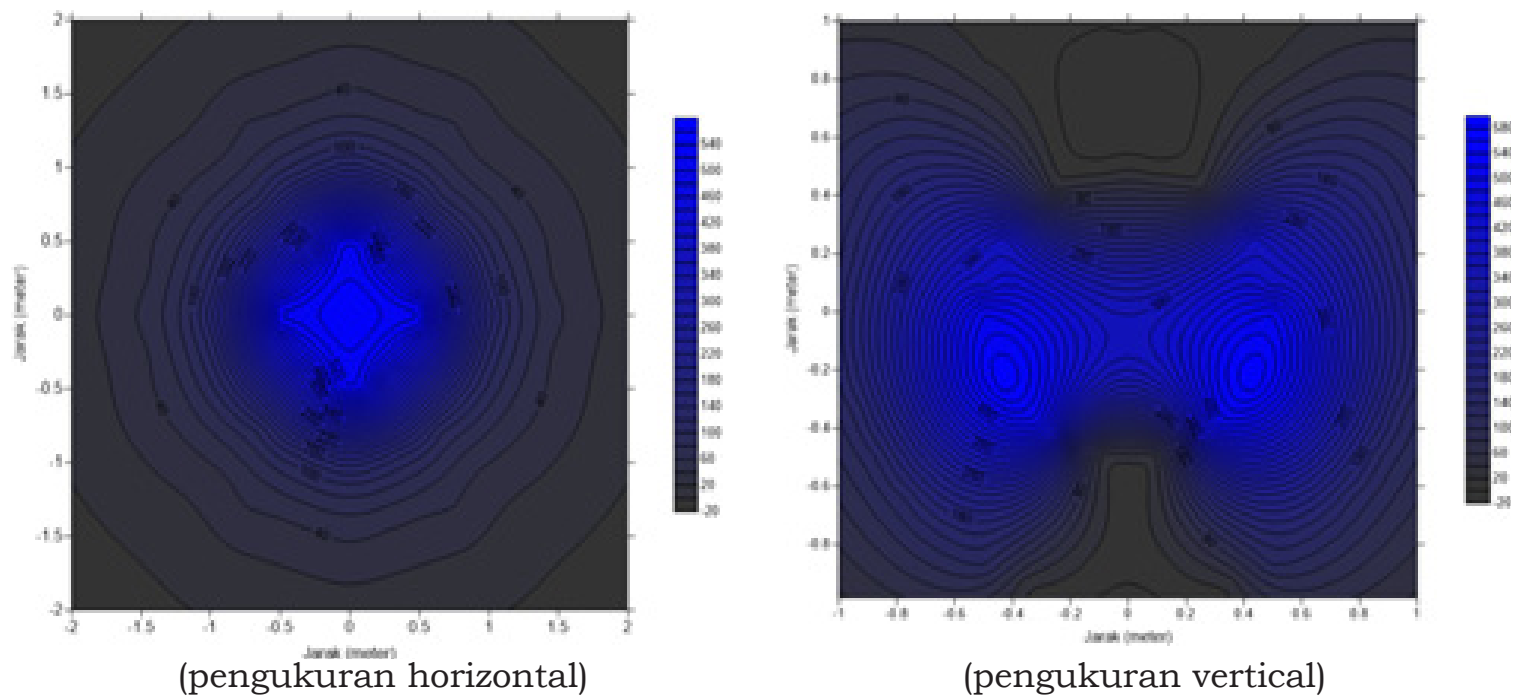

Gambar 10. Pola sebaran cahaya biru 


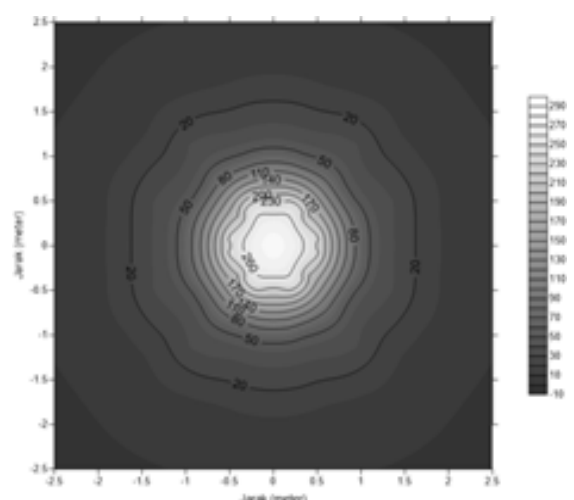

(pengukuran horizontal)

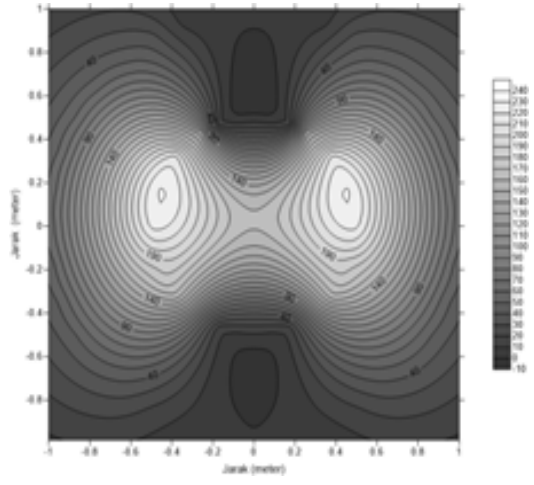

(pengukuran vertikal)

Gambar 11. Pola sebaran cahaya putih
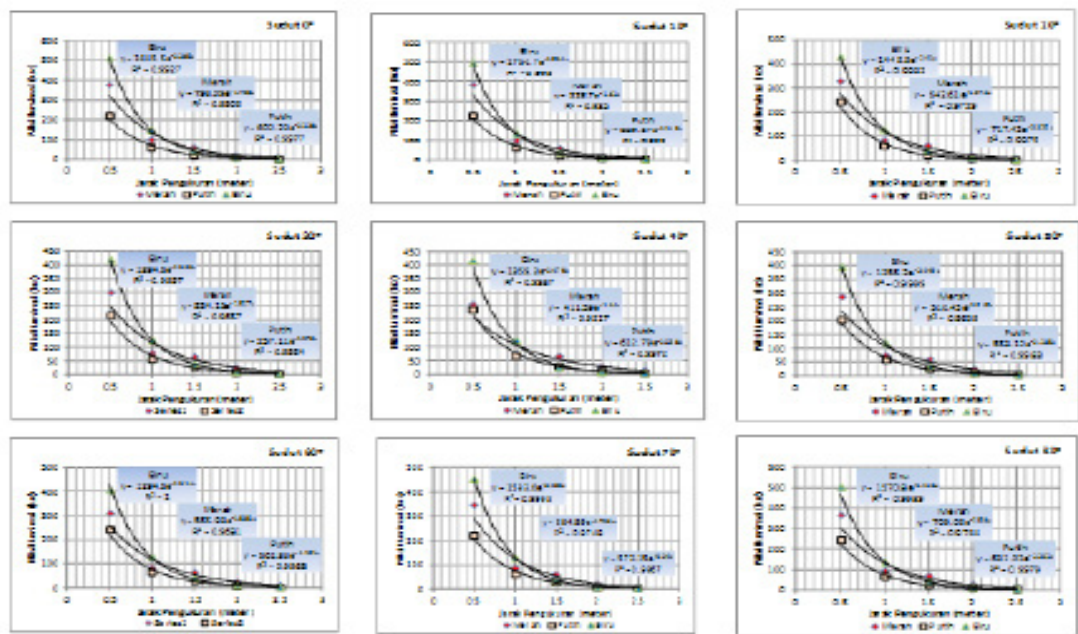

Gambar 12. Pola eksponensial iluminasi cahaya pada setiap sudut pengukuran

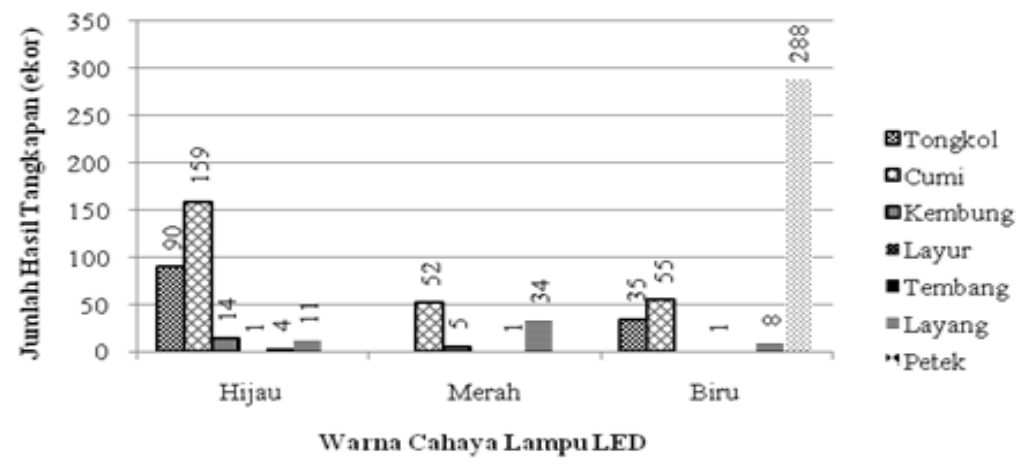

Gambar 13. Hasil Tangkapan pada warna lampu LED yang Berbeda
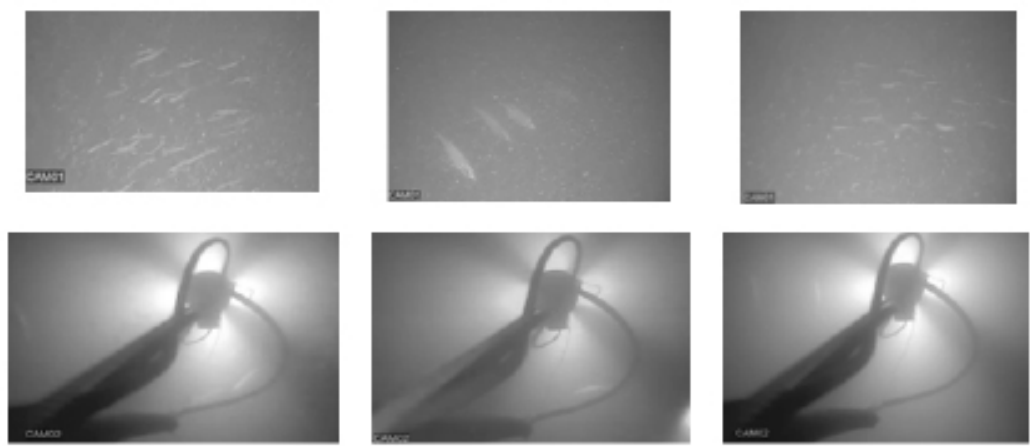

Gambar 14. Hasil Dokumentasi Rekaman Video Kamera Lampu LED dalam Air (diolah) 


\section{KESIMPULAN DAN SARAN}

\section{Kesimpulan}

Kontruksi lampu LED dalam air menggunakan lampu jenis RGB High Power LED 10 watt sebanyak 15 buah, 12 buah dipasang pada 4 sisi samping dan 3 buah dipasang pada sisi bawah. Sebagai bahan pembungkus dan sekaligus pelindung lampu digunakan material akrilik dan resin, dimana dari hasil uji tekan, material ini mampu menahan beban sebesar 914.27 $\mathrm{kgf} / \mathrm{cm}^{2}$ untuk material resin dan 1238.65 $\mathrm{kgf} / \mathrm{cm}^{2}$ untuk material aklirik jauh lebih tinggi dibandingkan beban atau tekanan hidrostatis yang akan diterima ketika alat dioperasikan yaitu kisaran 2-3 atm atau 2.06-3.09 $\mathrm{kgf} / \mathrm{cm}^{2}$, sehingga material ini memenuhi kriteria sebagai pembungkus lampu. Hasil pengukuran nilai iluminasi cahaya, menunjukkan nilai iluminasi cahaya yang dihasilkan berkisar antara 73-101 lux pada pengukuran horizontal dan antara 2-107 lux pada pengukuran vertikal cahaya warna merah, antara 110-151 lux pada pengukuran horizontal dan antara 2-171 lux pada pengukuran vertikal cahaya warna biru, dan antara 58-68 lux pada pengukuran horizontal dan antara 2-65 lux pada pengukuran vertikal cahaya warna putih. Nilai tersebut masih dalam kisaran fully adapted beberapa ikan sehingga iluminasi cahaya lampu memenuhi kriteria untuk alat bantu penangkapan ikan. Berdasarkan ujicoba penangkapan lampu LED bawah air terbukti mampu mengumpulkan gerombolan ikan

\section{Saran}

Perlu dilakukan lebih banyak ujicoba dan perhitungan analisis ekonomi untuk memastikan apakah alat hasil penelitian benar-benar efektif dan efisien dalam kegiatan usaha penangkapan ikan.

\section{DAFTAR PUSTAKA}

Baskoro MS. 2000. Capture process of the floated bamboo-platform liftnet with light atrraction. Doctoral Course of Marine Scienses and Technology: Graduate School of Fisheries, Tokyo University of Fisheries.

Ben Yami BM. 1976. Fishing with light. England: Published by Arrangement with FAO of The United Nations by Fishing News Books Ltd. Surrey.

Haygreen, Bowyer. 1987. Hasil Hutan dan Ilmu Kayu. Yogyakarta: Gadjah mada University Press.

Hua LT, Xing J. 2013. Research on LED fishing light. Research Journal of Applied Sciences, Engineering and Technology. 5(16):4138-4141

Shen SC, Huang HJ. 2012. Design of LED fish lighting attractors using horizontal/ vertical LIDC mapping method. OPTICS EXPRESS. Vol 20.

Subani B. 1989. Alat penangkapan ikan dan udang di Indonesia. Jurnal Penelitian Perikanan Laut. Nomor 50 Tahun 1988/1999. Edisi Khusus. Jakarta: Balai Penelitian Perikanan Laut, Badan Penelitian Perikanan Laut, Departemen Pertanian.

Sudirman, Baskoro MS, Purbayanto A, Safrudin, Suratman. 2006. Hubungan antara kecerahan perairan dan kecepatan arus dengan hasil tangkapan dan pengoperasian bagan rambo di selat makassa.Jurnal Ilmiah Sorihi. 1(5):82-104

Callister Jr. 2004 . An Introduction Materials Science and Engineering. Wiley.

Smith WF. 1996 . Principle of Materials Science and Engineering. Mc Graw Hill.

Wollburg P, Mills E. 2013. Alternatives to fuel-based lighting for night fishing field tests of lake and ocean applications in East Africa. Technical Report. USA :University of California 